Prima Parte-Acta9:00_Prima Parte(Ale+Lena).qxd 12-12-2006 16:44 Pagina i

Globalization and Education 
Prima Parte-Acta9:00_Prima Parte(Ale+Lena).qxd 12-12-2006 16:44 Pagina ii

Edited by

The Pontifical Academy of Sciences and of Social Sciences
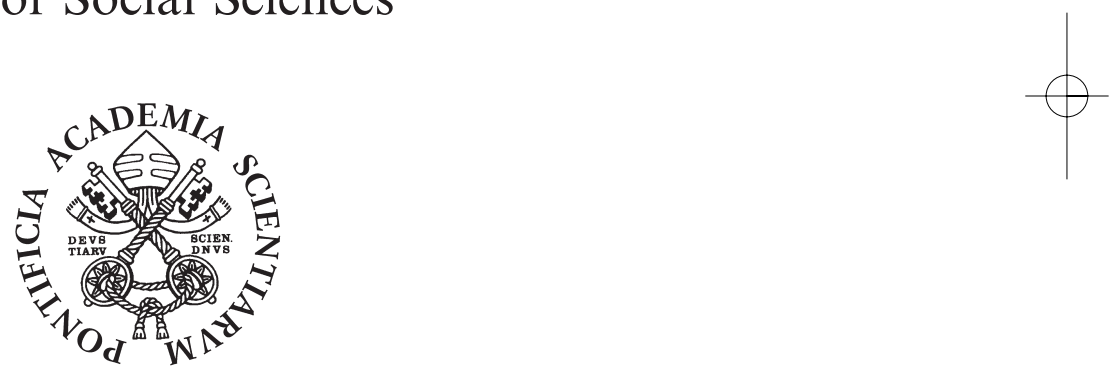


\title{
Globalization and Education
}

\author{
Proceedings \\ of the \\ Joint Working Group \\ The Pontifical Academy of Sciences \\ The Pontifical Academy of Social Sciences \\ 16-17 November 2005 \\ Casino Pio IV \\ edited by \\ Marcelo Sánchez Sorondo \\ Edmond Malinvaud \\ Pierre Léna
}

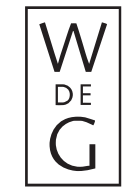

Walter de Gruyter · Berlin · New York 
The opinions expressed with absolute freedom during the presentation of the papers of this meeting, although published by the Academies, represent only the points of view of the participants and not those of the Academies.

@ Printed on acid-free paper which falls within the guidelines of the ANSI to ensure permanence and durability.

A CIP catalogue record for this book is available from the Library of Congress.

ISBN 978-3-11-019113-4

Bibliographic information published by the Deutsche Nationalbibliothek

The Deutsche Nationalbibliothek lists this publication in the Deutsche Nationalbibliografie; detailed bibliographic data are available in the Internet at http://dnb.d-nb.de.

(c) Copyright 2007 by Walter de Gruyter GmbH \& Co. KG, 10785 Berlin, Germany. All rights reserved, including those of translation into foreign languages. No part of this book may be reproduced or transmitted in any form or by any means, electronic or mechanical, including photocopy, recording or any information storage and retrieval system, without permission in writing from the publisher.

Printed in Germany.

Cover design: Martin Zech, Bremen.

Printing and binding: Hubert \& Co. GmbH \& Co. KG, Göttingen. 


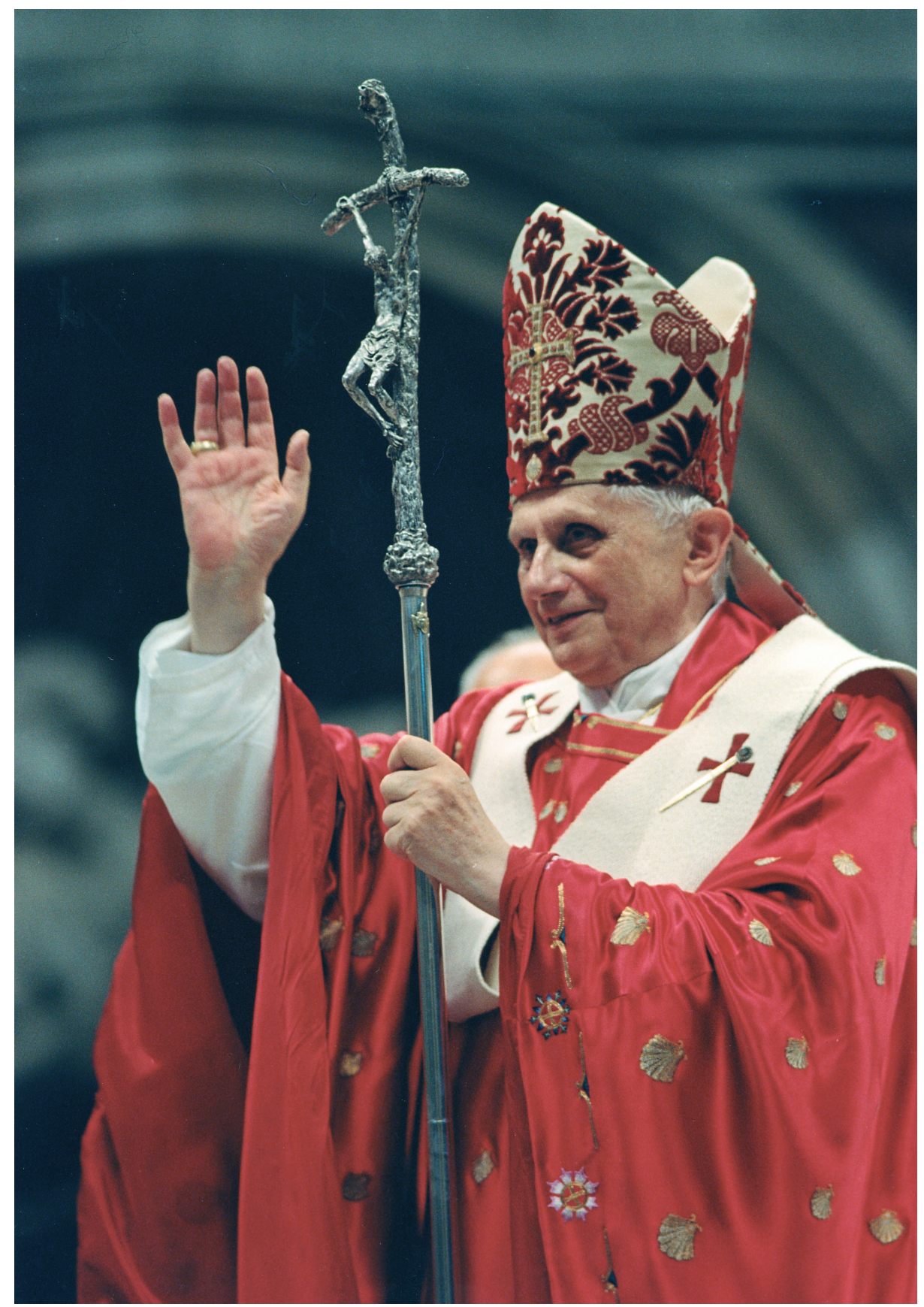

Pope Benedict XVI

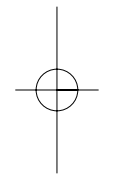




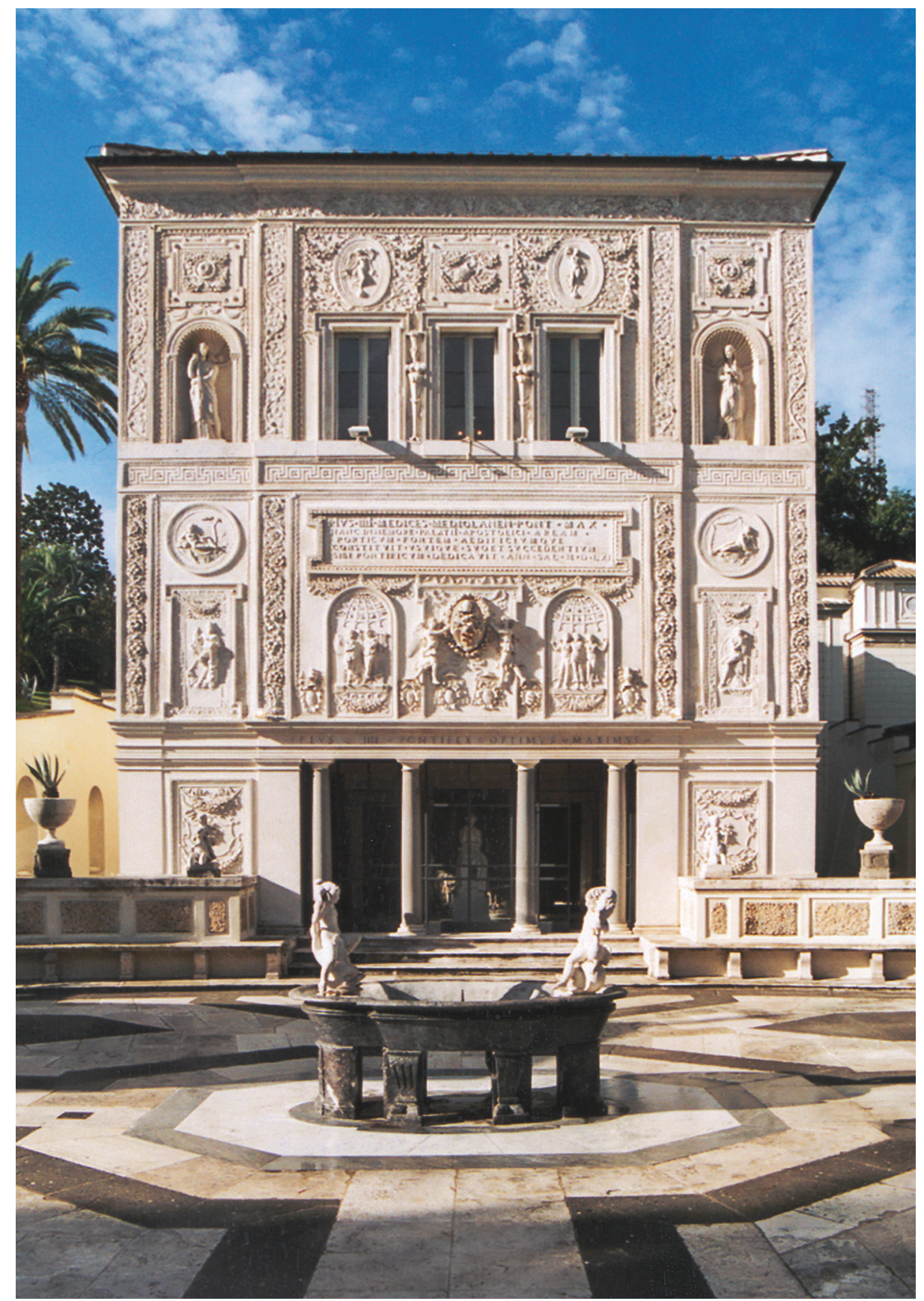

The Pontifical Academy of Sciences, Casina Pio IV 


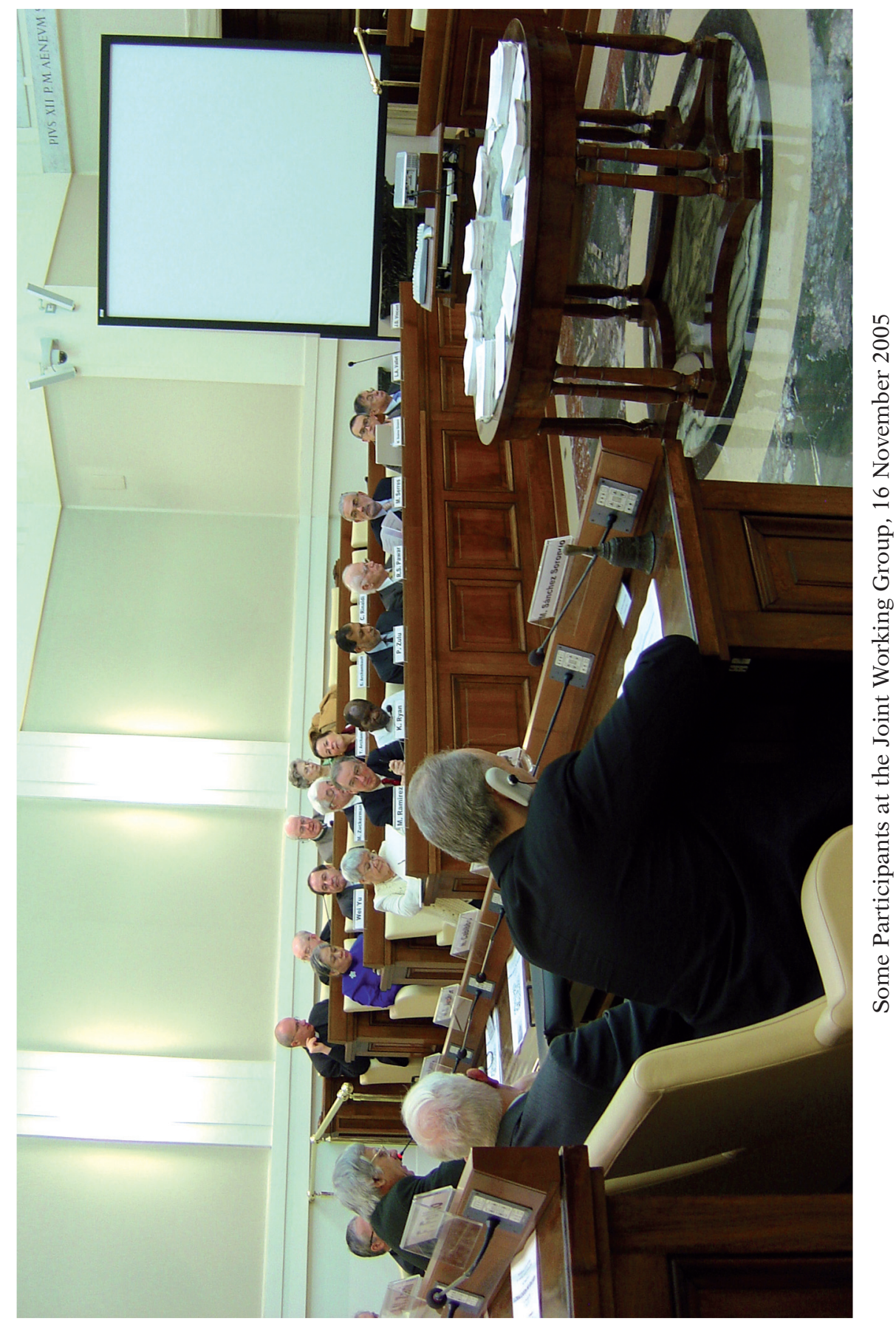




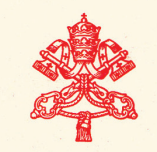

SECRETARIAT OF STATE

No. 17.731

From the Vatican, 16 November 2005

Your Excellency,

His Holiness Pope Benedict XVI was pleased to learn that the Pontifical Academy of Sciences would be meeting on 16-17 November 2005 to discuss the theme of Globalization and Education, and he sends warm greetings to all those participating in this important gathering.

A constant and concrete reflection on the mission of education in modern culture is one that is marked by a healthy exchange of ideas. Our shared historical experience in this field finds a common source in the natural desire to know truth, goodness and beauty. It is this longing which moves and nurtures each man and every culture. As Aristotle observed: 'All men naturally desire knowledge'. Indeed, the capacity to be educated is a characteristic which sets men and women apart from other creatures. Like all human endeavours, education first and foremost is centred on man: it is man who is educated, it is man who educates and, accordingly, it is man who is the subject of education.

His Holiness prays that this conference will make a major contribution in discerning ways to improve the training of present and future generations by helping others to realize that in our today's world there is an urgent need to provide a good education to all regardless of religious conviction, ethnic background or economic status. He earnestly hopes that this meeting will help all those involved in the task of human formation to be mindful that it is the human person, open to God, who is at the centre, the beginning, and the end of the educational process. Upon all those taking part in this meeting he invokes God's blessings of wisdom and peace.

With fraternal best wishes, I am

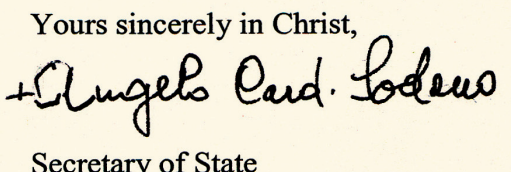

The Most Reverend Marcelo Sánchez Sorondo

Chancellor

Pontifical Academy of Sciences

Casina Pio IV

Roma

Message of His Holiness Benedict XVI 